\title{
Biomass Pre-Processing Size Reduction with Instrumented Mills
}

\author{
A.R. Womac \\ University of Tennessee, 2506 E.J. Chapman Dr, Knoxville, TN \\ C. Igathinathane \\ Mississippi State University \\ P. Bitra \\ University of Tennessee
}

P. Miu

Fmr. University of Tennessee

T. Yang

University of Tennessee

\section{S. Sokhansanj}

Oak Ridge National laboratory

\section{S. Narayan}

First American Scientific

\author{
Written for presentation at the \\ 2007 ASABE Annual International Meeting \\ Sponsored by ASABE \\ Minneapolis Convention Center \\ Minneapolis, Minnesota \\ 17 - 20 June 2007
}

\begin{abstract}
Rotary size reduction equipment were instrumented to identify important operating parameters with the aim of minimizing energy consumption while reducing the size of lignocellulosic biomass. Size reduction equipment included a knife mill, hammer mill, and disc mill. Monitored parameters included input power and particle size distributions.. Operating parameters included angular velocity, mass rate, screen size, and biomass selection. Results indicated optimum operating conditions with minimal energy input. Geometric mean dimensions of biomass particles varied from $5 x$ for particle length to $0.3 x$ for particle width when comparing actual to ASABE sieve results highlighting the need for better consensus standards on particle size reporting.
\end{abstract}

Keywords. grinders, slicers, energy, lignocellulose, particle size, sieve, image analysis 


\section{Introduction}

Biomass processing and use typically requires a degree of particle size reduction. Tub grinders for forest and wood residues are typically vertical axis hammermills that repeatedly apply impact and tensile forces to the residue until it reaches a size small enough to pass through the selected screen size. Grind size for gasification was $6.4 \mathrm{~mm}$ (Raman et al., 1981). Corn stover was ground to 20 mesh for acid hydrolysis in making ethanol (Foutch, 1981). Size-reduction intensive processes for some chemical conversion processes rely on grinding the biomass to a particle size on the order of $1 \mathrm{~mm}$, which requires 1/3 of the total conversion power (Walsum et al. 1996). One U.S. Patent (5,677,154, Production of ethanol from biomass) verified nominal sizes of $\sim 1$ to $6 \mathrm{~mm}$. Size reduction may be accomplished with multiple-stage grinding process.

Hill and Pulkinen (1988) and Samson et al. (2000) investigated size reduction using hammermills for pelletizing alfalfa and switchgrass. Balk (1964) related hammer mill specific energy to moisture content and feed rate of coastal Bermuda grass. Samson et al. (2000) reported a specific energy consumption of $44.9 \mathrm{kWh} / \mathrm{t}$ for a hammer mill with a screen size of $5.6 \mathrm{~mm}$ with switchgrass. Moisture content, bulk density, true density and particle size and shape of biomass particles after grinding were important for downstream processing for 62 kinds of biomass (Ebling and Jenkins, 1985). Mani et al. (2002) found an average specific grinding energy consumption of over $60 \mathrm{~kW}$-h/t for switchgrass (8 \% w.b.) to a geometric mean chop size of $\sim 7 \mathrm{~mm}$ from a hammer mill.

Comprehensive knowledge of particle size reduction of biomass is lacking in scientific literature. For minerals, power $=(\text { particle size })^{\wedge} 3 / 2$ and is related to molecular bonds. Size reduction knowledge for biomass would allow best selection of equipment types for the material, decreased operating costs, and aid in the predictable delivery of uniform quality biomass for processing and conversion. Size reduction performance depends on the combined effect of failure stresses applied to material, material condition such as moisture, and on the equipment operating parameters such as classifying screen size, rotary speed (rpm), and mass throughput. These measures would assist in predicting the most basic size reduction parameters such as energy use and resulting particle size distribution - which lead to informed decisions to improve process design.

Objectives:

- Implement common-platform instrument system suitable for a range of rotary mills

- Examine performance data for a selected mill to reduce input energy

- Determine representative particle size spectra resulting from selected mill

\section{Methods and Materials Mills and instrumentation}

Three bare mills (knife mill, hammer mill, and disk mill) were obtained and special-purpose frames were engineered to allow direct monitoring of input mechanical energy. Direct inputenergy measurement was elected, in lieu of indirect, integrative measures such as measuring fuel use, to observe characteristic peaks and frequencies associated with operating variables.

The three developed instrumentation approaches for each mill were identical (Figs 1, 2, 3). Briefly, a calibrated torque and speed sensor (Series 4200 PCB Piezotronics, Depew, NY) was inserted in the power-transmitting driveline between an $18 \mathrm{~kW}(24 \mathrm{hp})$ gasoline engine and each mill. Measurement torque capacity was $226 \mathrm{~N}-\mathrm{m}$ (2000 in-lb) with full scale accuracy of $0.1 \mathrm{~N}-\mathrm{m}$ 
( 1 in-lb). An engine prime mover was selected to facilitate operating mills at various rotational speeds. Changing speeds was simply a matter of adjusting the engine-governed speed via the throttle setting.

Data were collected via analog to digital signal processing modules and stored on a laptop computer, all using Labview 8 software (Austin TX). Sensor polling was conducted up to 24,000 $\mathrm{Hz}$ and interval averages were stored up to several thousand $\mathrm{Hz}$. Lesser polling and storage frequencies were used on many test runs to more easily facilitate dragging and dropping data into an Excel spreadsheet for analysis ( 65,000 line storage limit, $\sim 30,000$ line arithmetic limit).
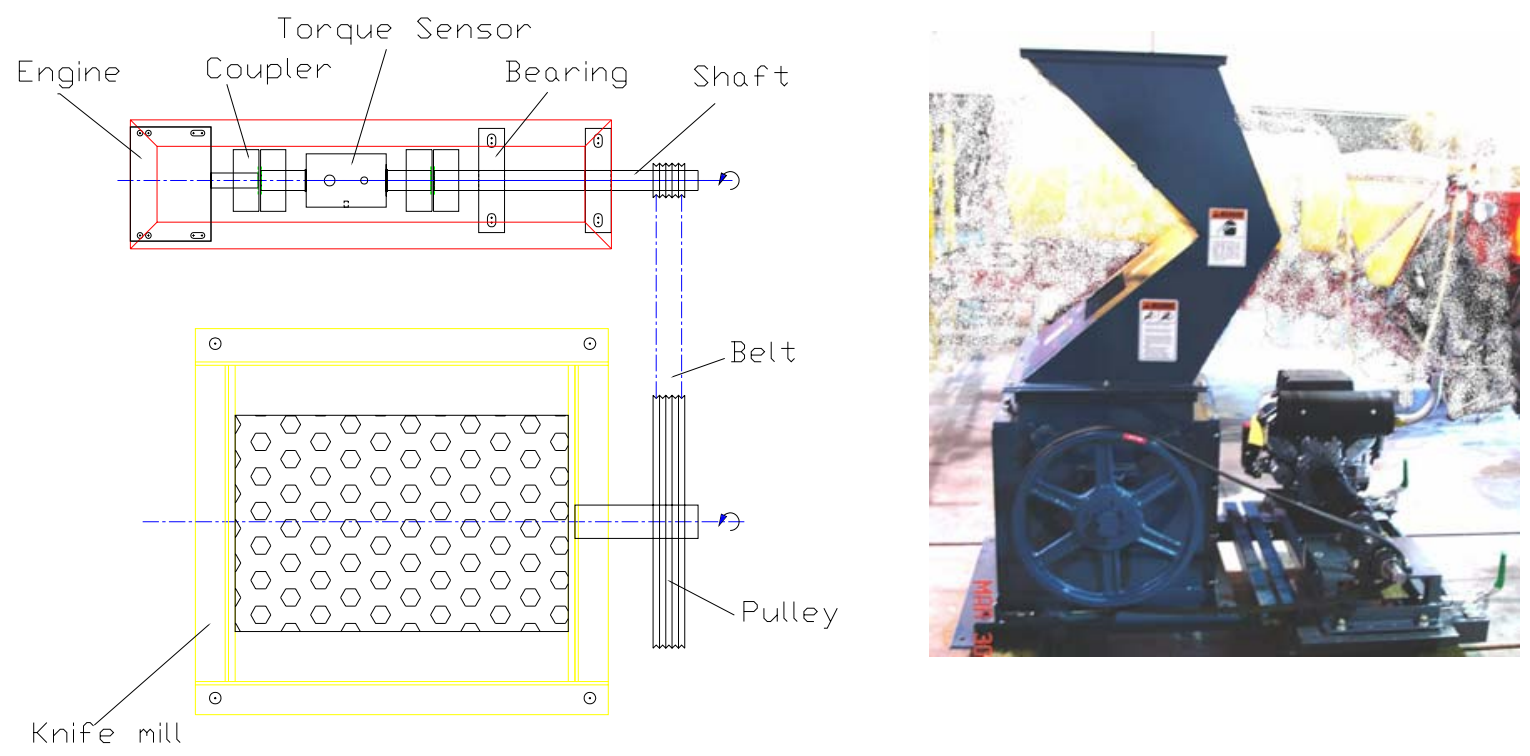

Figure 1. Overhead sectional view of knife mill and instrumentation set up, and photo with belt guard removed.

\section{Methods}

In-depth tests reported herein examined the knife mill with emphasis on operation with switchgrass. Various combinations of knife mill screen sizes, mass flow rates, and angular velocity of mill were examined for power, specific energy, and particle sizes. Particle sizes were determined using ASABE forage sieve methods (ANSI/ASAE S424.1, DEC01, 2006) and image analysis of sample particles (Simonton and Pease, 1993), all to determine geometric mean dimensions (GMD). A flat bed scanned image with none-touching biomass samples was input for image analysis of major and minor dimensions. Third particle dimension was assumed equal to the minor dimension. Overall, emphasis was placed on:

- Factors affecting energy efficiency of size reduction

- Actual representative particle sizes compared to sieve results 

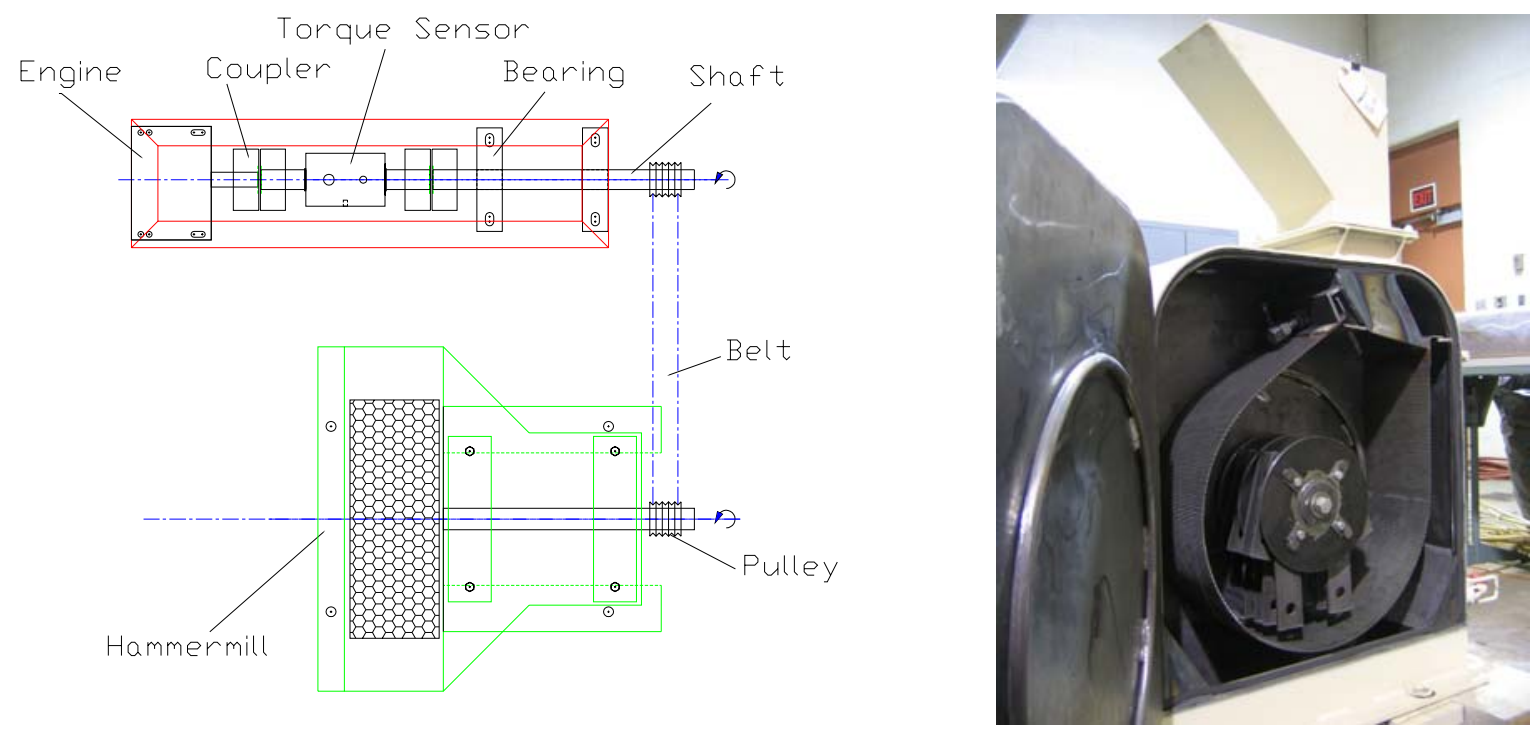

Figure 2. Hammer mill and instrumentation setup, and photograph of open hammermill.
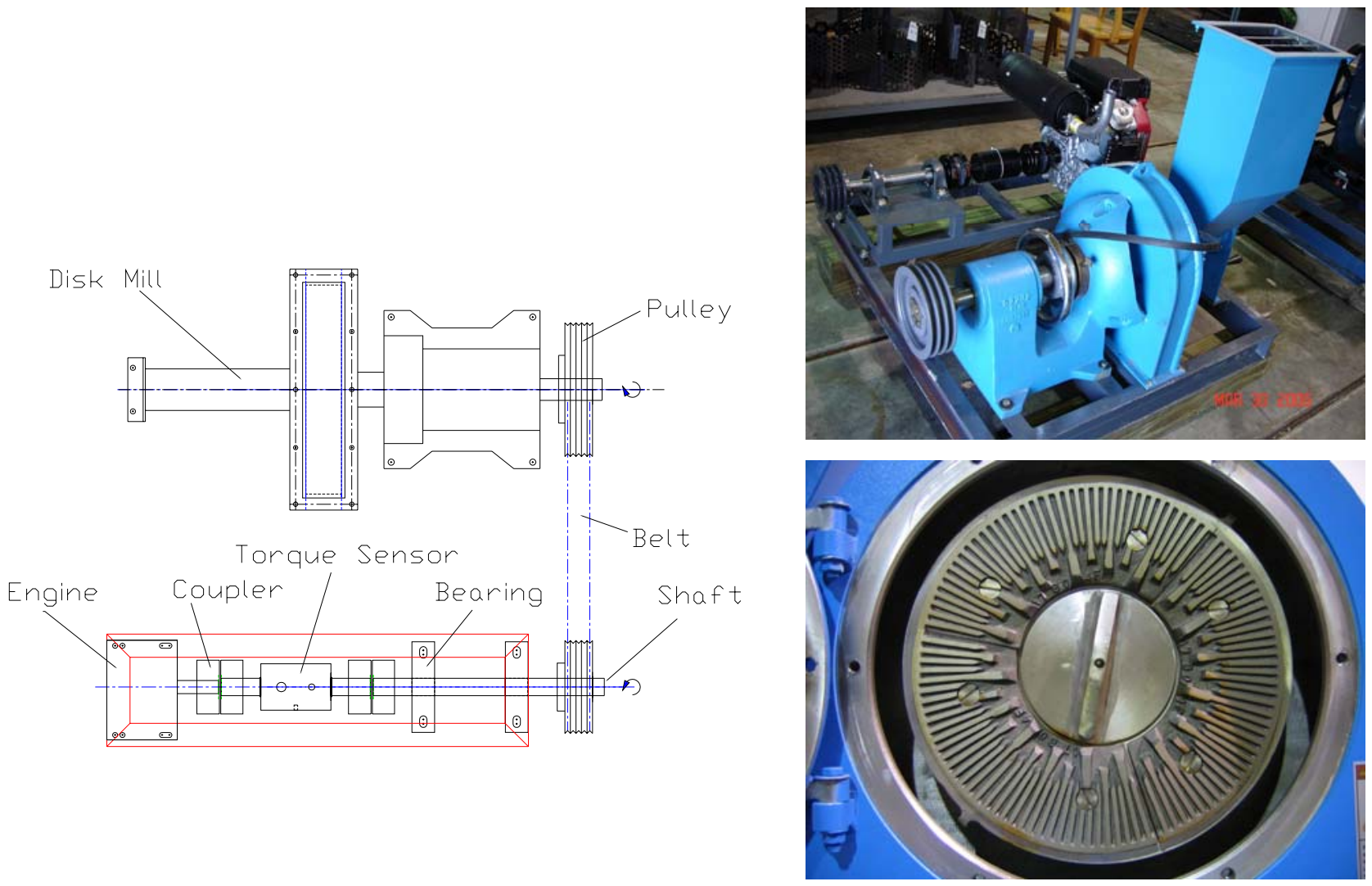

Figure 3. Disk mill and instrumentation setup, and photographs of disk refiner. 


\section{Results}

\section{Power and size reduction energy}

Parasitic power losses for size reduction equipment such as the knife mill operated without biomass input increased as angular velocity (speed) increased (Fig. 4). Power increased quadratic with speed for the presented data of the knife mill with a 12.7-mm screen, and was similar for other screen sizes. Since pump and fan laws indicate power increase with the cube of speed, fan effect of an unloaded mill was minimal. Since data points represent constant speed operation without acceleration in angular velocity, increases in frictional losses of drive and bearings may account for increased power.

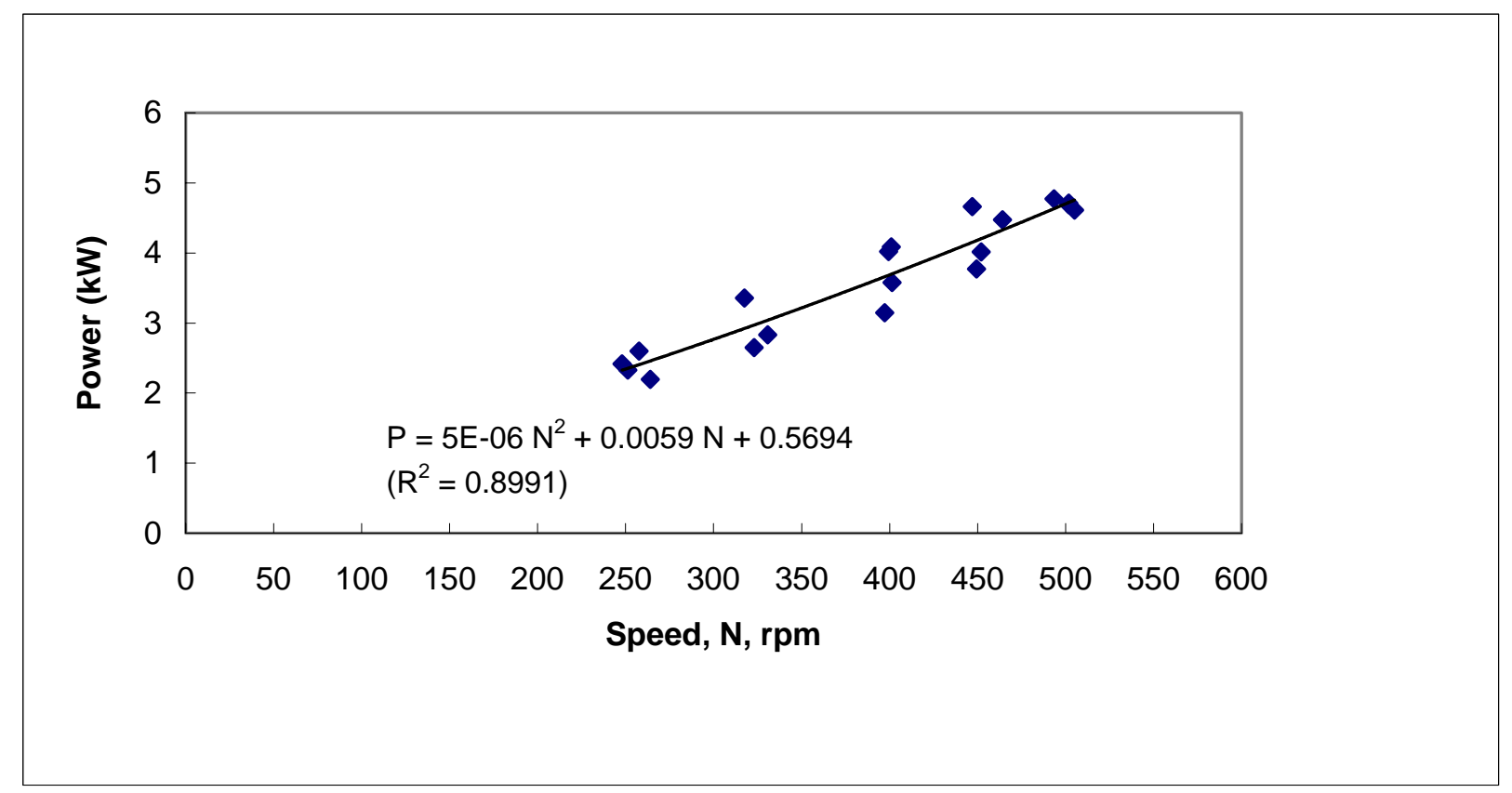

Figure 4. Knife mill parasitic power (operating without biomass) versus speed for low moisture switchgrass - for knife mill with screen openings of $12.7 \mathrm{~mm}$.

Total specific energy for size reduction also increased with the quadratic of speed (Fig. 5). Subtraction of parasitic power loss from the total specific energy gave a somewhat constant effective specific energy (Fig. 6). These results indicate that for size reduction with rotary equipment such as knife mills equipped with classifying screens, increased operating speed increases total specific energy likely through a mechanism of increased parasitic losses for the mill alone, not including losses associated with accelerating biomass input.

Size reduction energy hereafter are reported as total specific energy, since that reflects the actual input energy into the mill. 


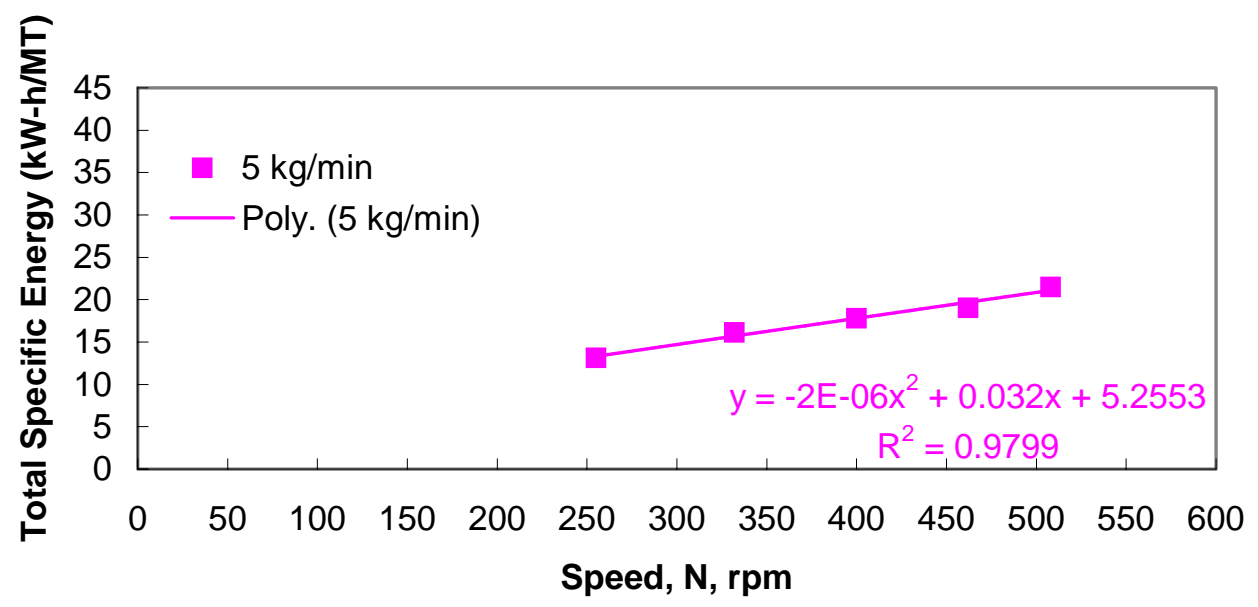

Figure 5. Total specific energy for size reduction of low-moisture switchgrass through a knife mill with 12.7-mm screen.

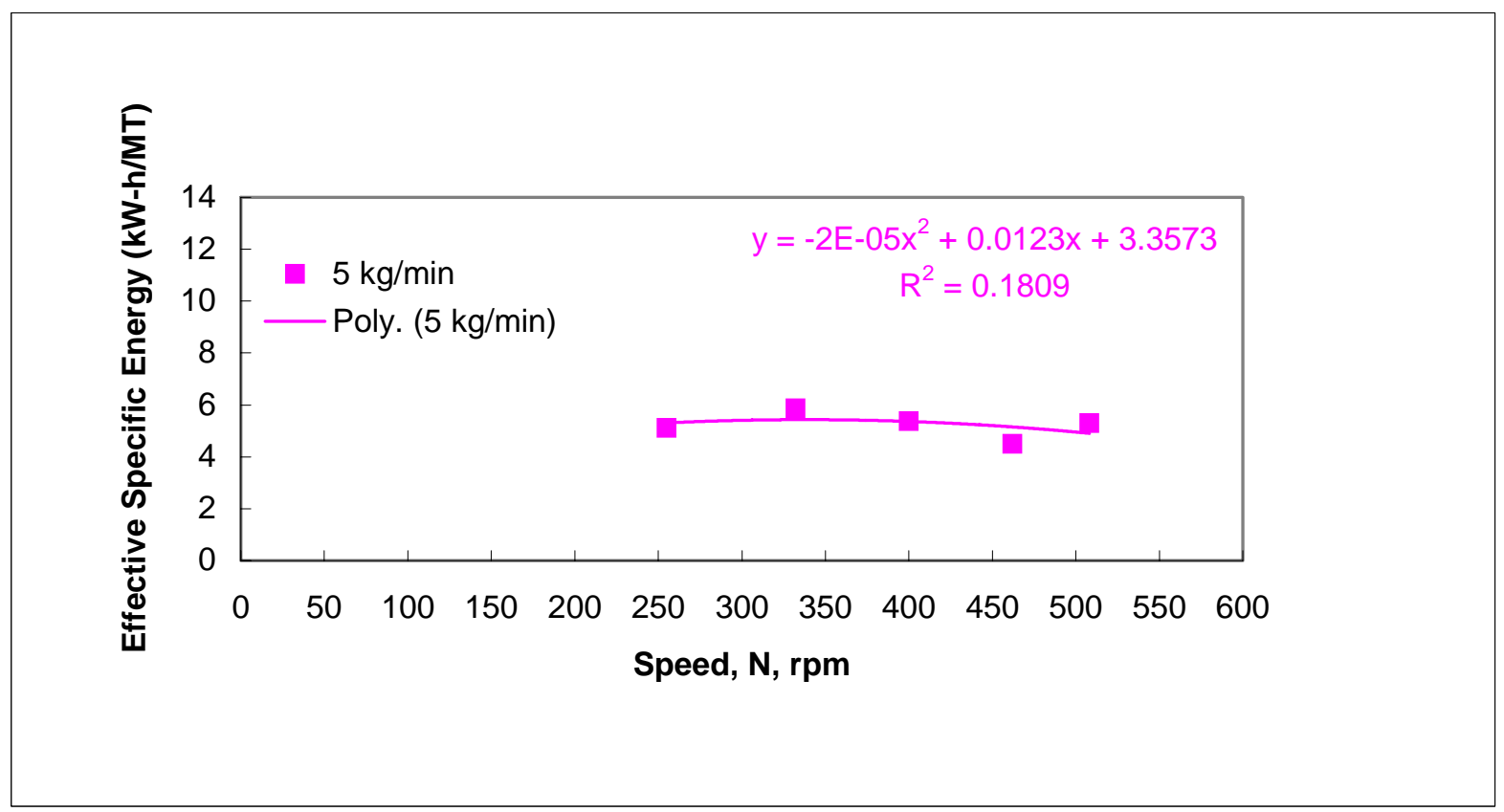

Figure 6. Effective specific energy for size reduction of low-moisture switchgrass through a knife mill with 12.7-mm screen. 
Figure 7 shows decreasing size reduction energy as low-moisture switchgrass input rate increases for a knife mill operated with three screen sizes at a mill speed of $500 \mathrm{rpm}$. Operating the mill at reduced capacity increases the proportion of parasitic power requirements relative to power reaching the biomass for size reduction. Also, a large increase in screen size required less energy.

This illustrates that optimum size reduction using the least energy relies on feeding the proper mass rate into the mill. Another implication is that multiple passes of material through the mill to further reduce particle sizes with a smaller screen than used in prior runs needs to take into account the fact that each pass increases the power lost to parasitic loads.

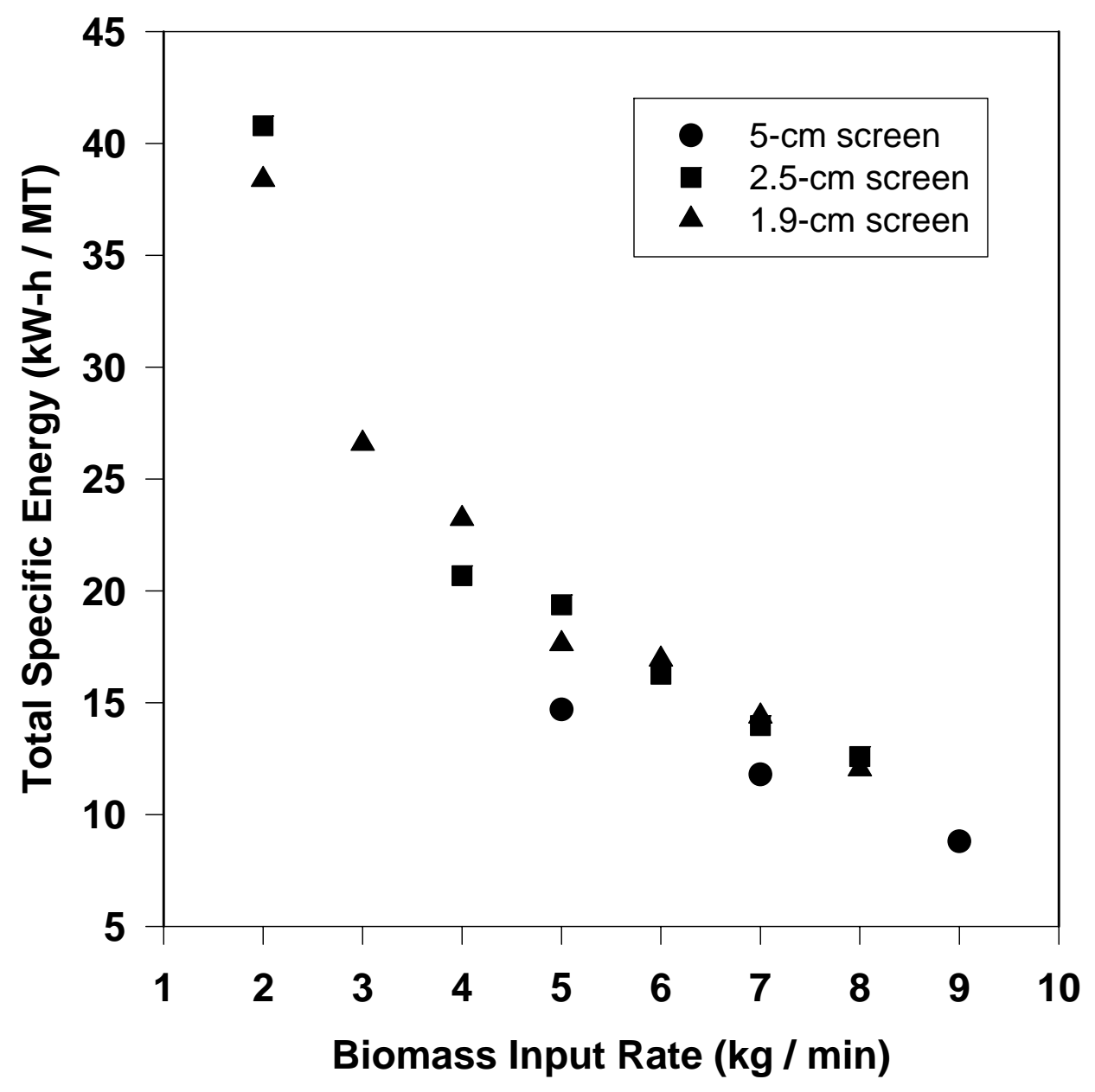

Figure 7. Total specific energy of size reduction versus biomass input rate for a knife mill with three screen sizes all operated at $500 \mathrm{rpm}$ with low-moisture switchgrass. 
Figure 8 plots size reduction energy versus rotational speed for a knife mill operated with two screen sizes at a constant low-moisture switchgrass input rate of $5 \mathrm{~kg} / \mathrm{min}$. The overall trend is that increased rotational speed required increased size reduction energy. This increase may be due to increased losses due to adding inertia to the switchgrass, increased frictional losses between screen and switchgrass, and parasitic power losses. A slight increase in size reduction energy was required for the smallest screen size, though it is small compared to the range of energy associated with rotation speed. Most efficient operation may require reduced operating speeds for biomass failure not requiring impact.

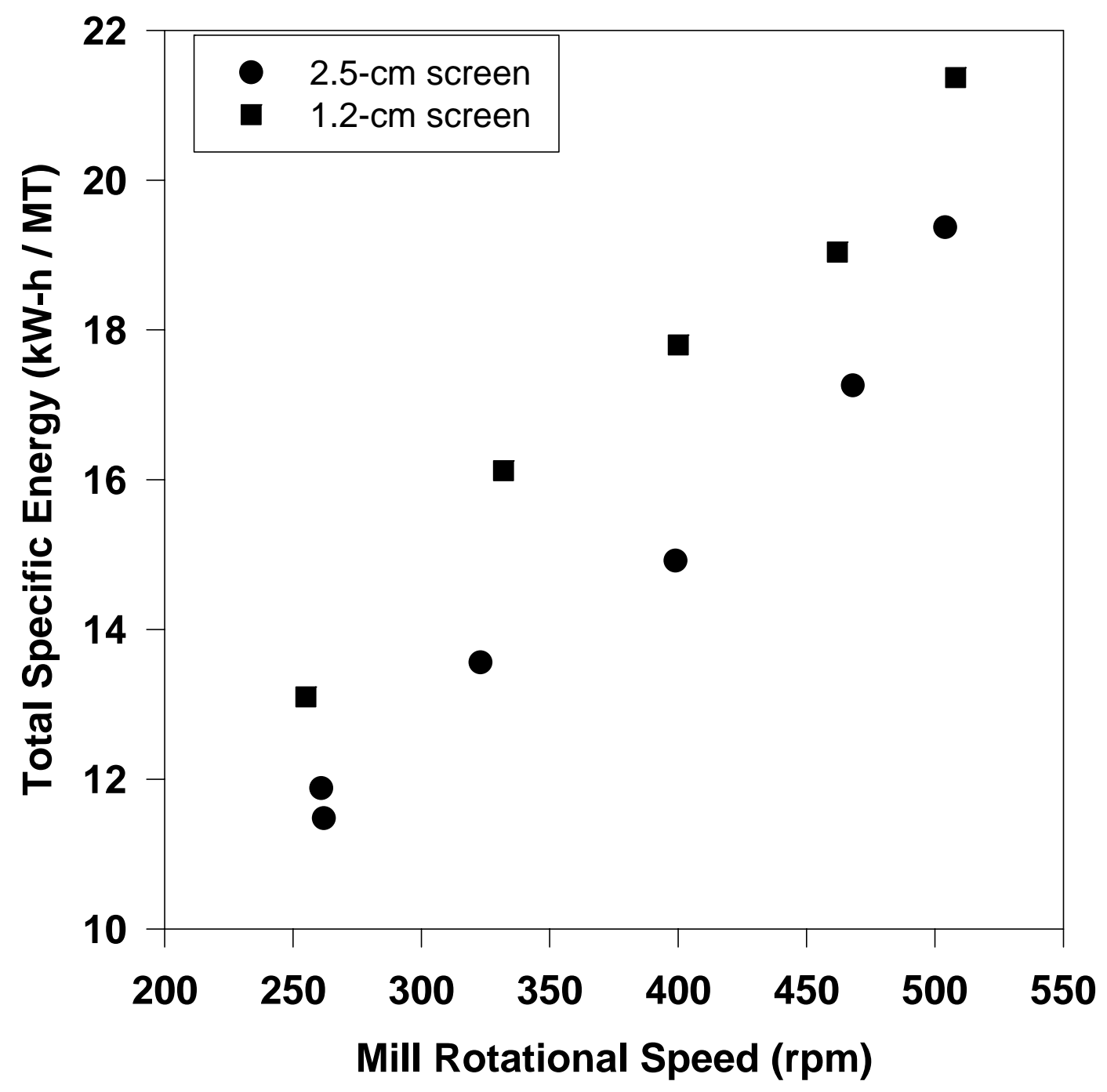

Figure 8. Total specific energy of size reduction measured for a knife mill operated at various rotational speeds with two screen sizes at a constant switchgrass input rate of $5 \mathrm{~kg} / \mathrm{min}$. 
Figure 9 shows size reduction energy versus input rate of low-moisture switchgrass into a knife mill operated at two rotational speeds and with a $1.9-\mathrm{cm}$ screen. Size reduction energy was more sensitive to mass input rate than rotational speed. Again, this shows the need to maximize flow rate and minimize speed for a knife mill that does not fail material by attrition and impact.

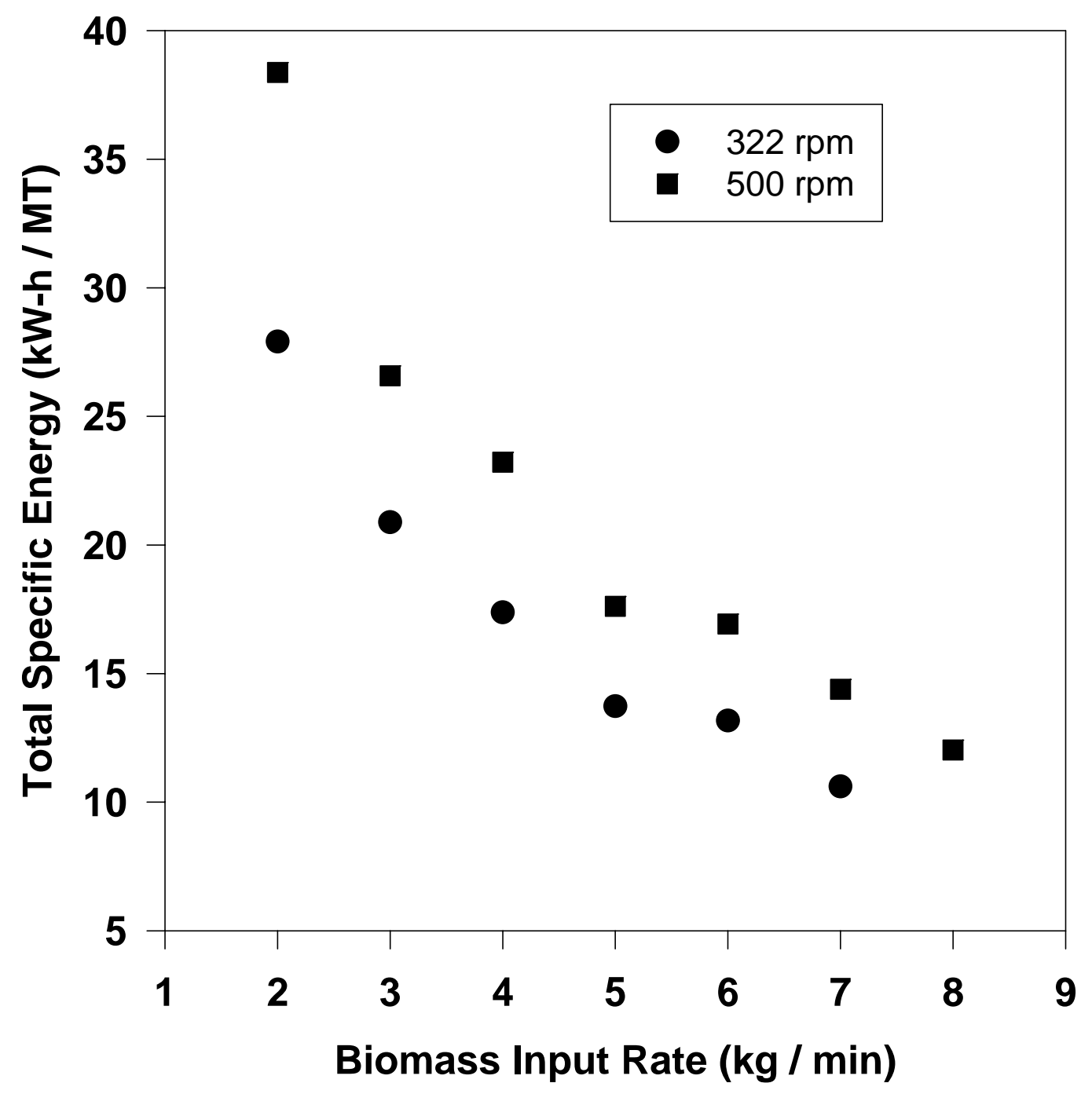

Figure 9. Total specific energy for size reduction versus input rate of dry switchgrass into a knife mill operated at two rotational speeds and with a $1.9-\mathrm{cm}$ screen. 


\section{Particle sizes}

Particle size distributions as determined by ASABE forage standard (ANSI/ASAE S424.1, DEC01, 2006) are shown in Figs 10 - 13 for various mass input rates and rotor speeds in a knife mill equipped with screen sizes of $12.7,19.0,25.4$, and $50.8 \mathrm{~mm}$, respectively. Decreased screen size resulted in decreased particle sizes, as expected. Of particular interest, knife mill screen size determined characteristic shapes in particle size spectra curves. For example, the $12.7 \mathrm{~mm}$ screen resulted in somewhat of a normal distribution in particle sizes, whereas the other screen sizes each had skewed normal distributions. Ratios of mass fractions contained in small versus large particles differed with the different screen sizes. The mass fraction differences depend not just on screen size, but also on the operating parameters such as mass input rate and rotor speed (as evidenced by the data spread in each figure).

Geometric mean dimensions GMD) of particle length, as calculated directly using sieve opening sizes and mass fraction on ASABE forage sieves, varied to some extent depending on biomass selection (Table1). Ratio of GMD to knife mill screen size ranged from 0.21 to 0.36 , with most ratios slightly less than 0.30 . For emphasis, GMD values were calculated based on ASABE sieve sizes and mass fraction on each sieve.

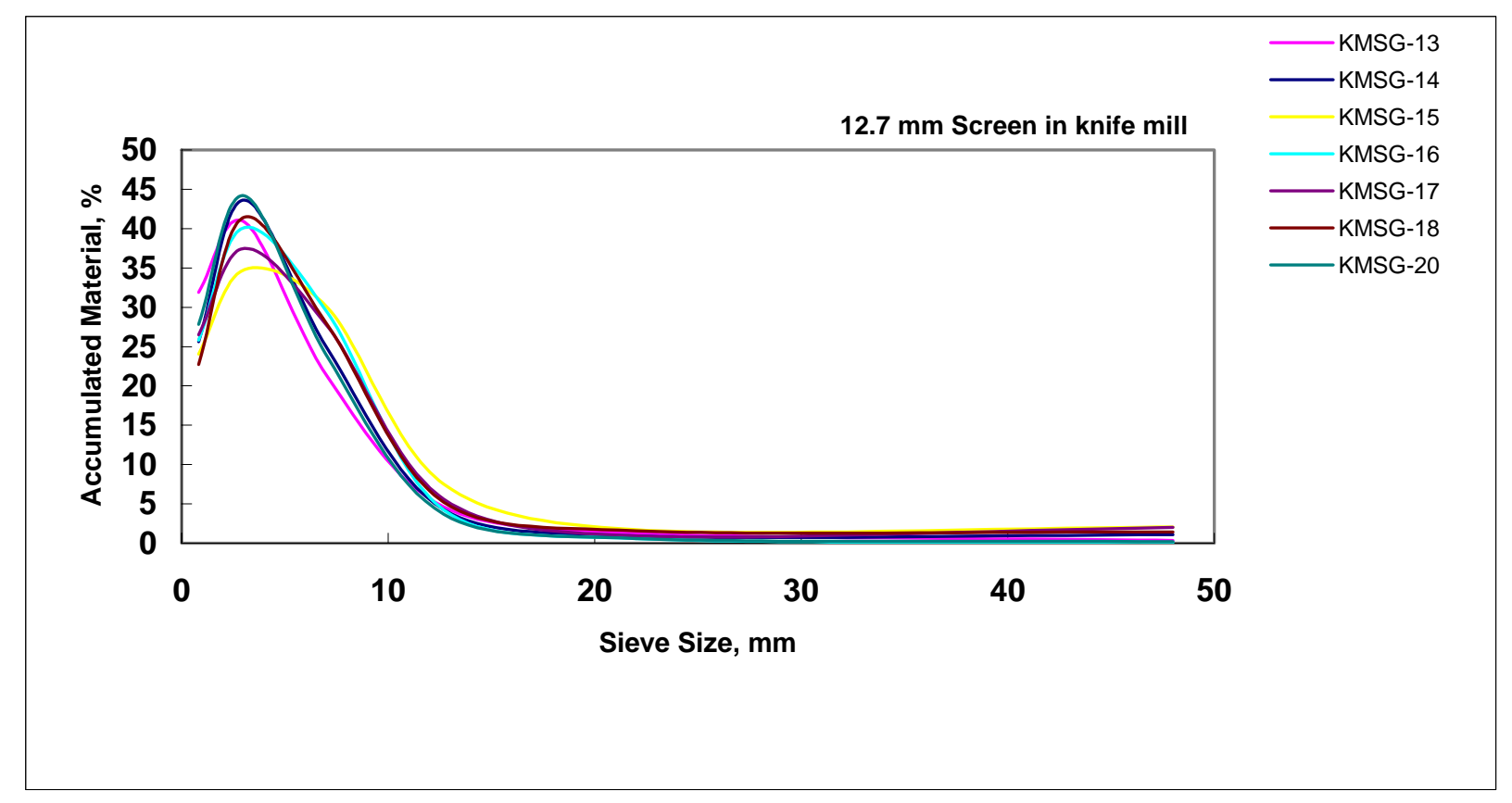

Figure 10. Sieve particle size results for switchgrass size reduction at various mass input rates and rotor speeds in a knife mill equipped with a $12.7 \mathrm{~mm}$ screen. 


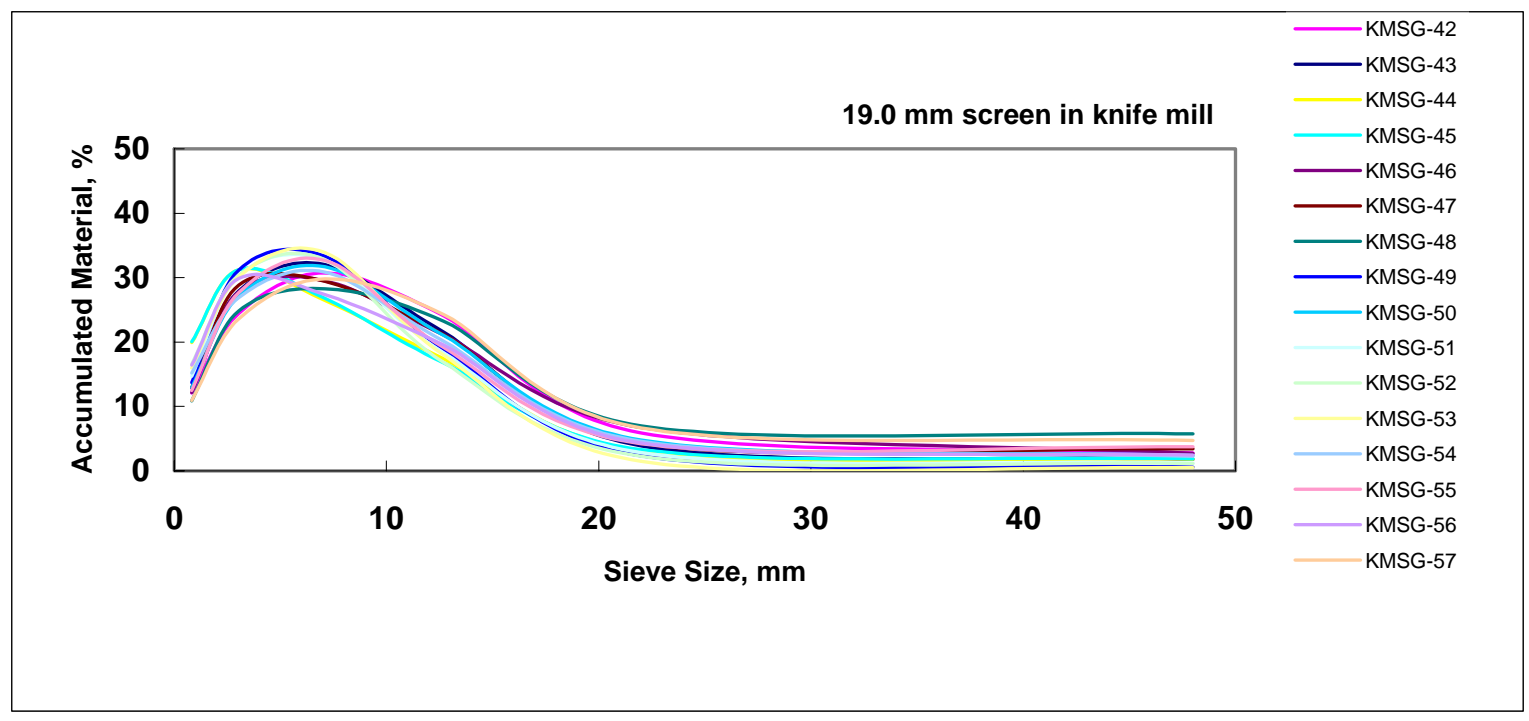

Figure 11. Sieve particle size results for switchgrass size reduction at various mass input rates and rotor speeds in a knife mill equipped with a $19.0 \mathrm{~mm}$ screen.

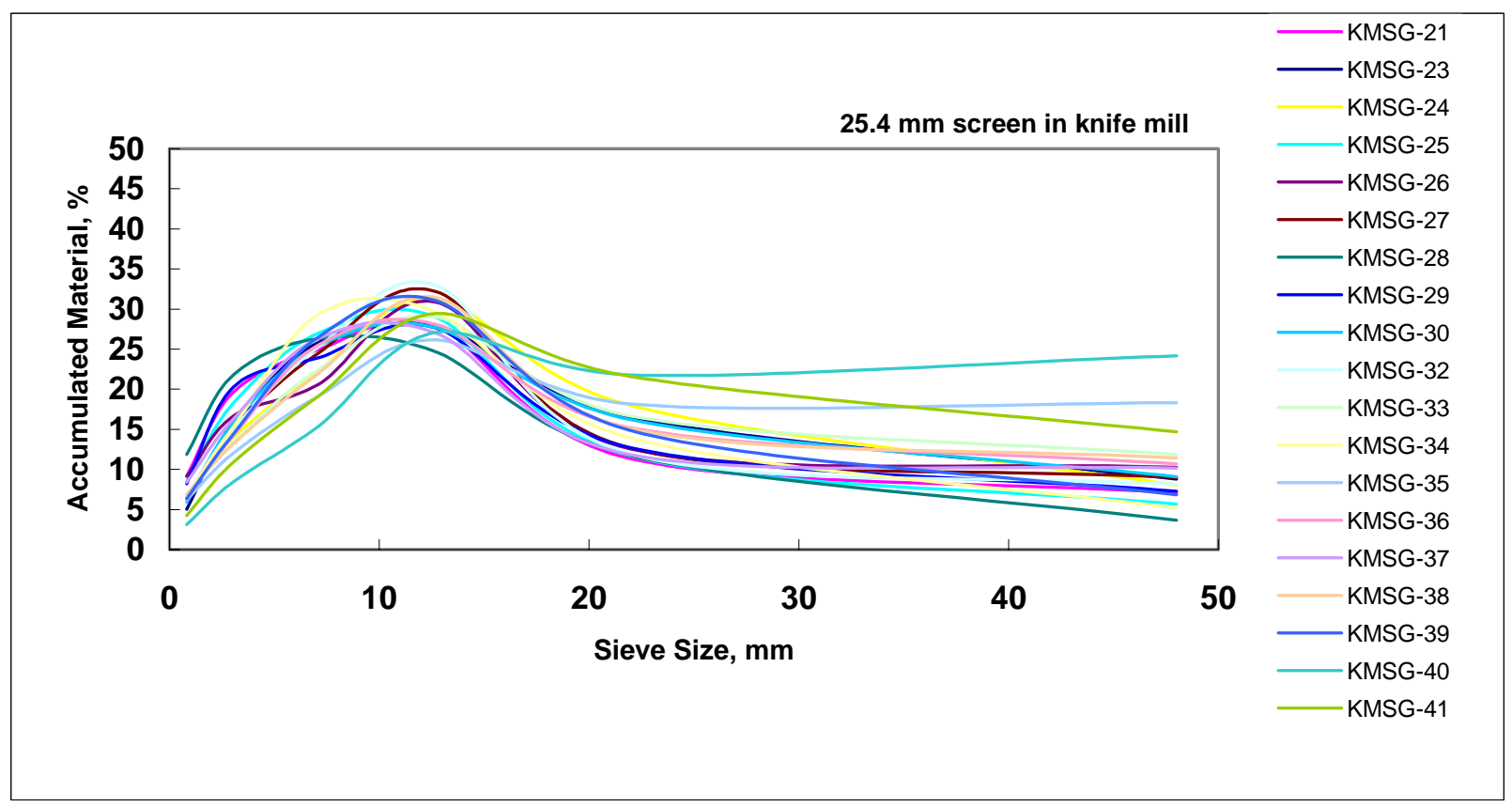

Figure 12. Sieve particle size results for switchgrass size reduction at various mass input rates and rotor speeds in a knife mill equipped with a $25.4 \mathrm{~mm}$ screen. 


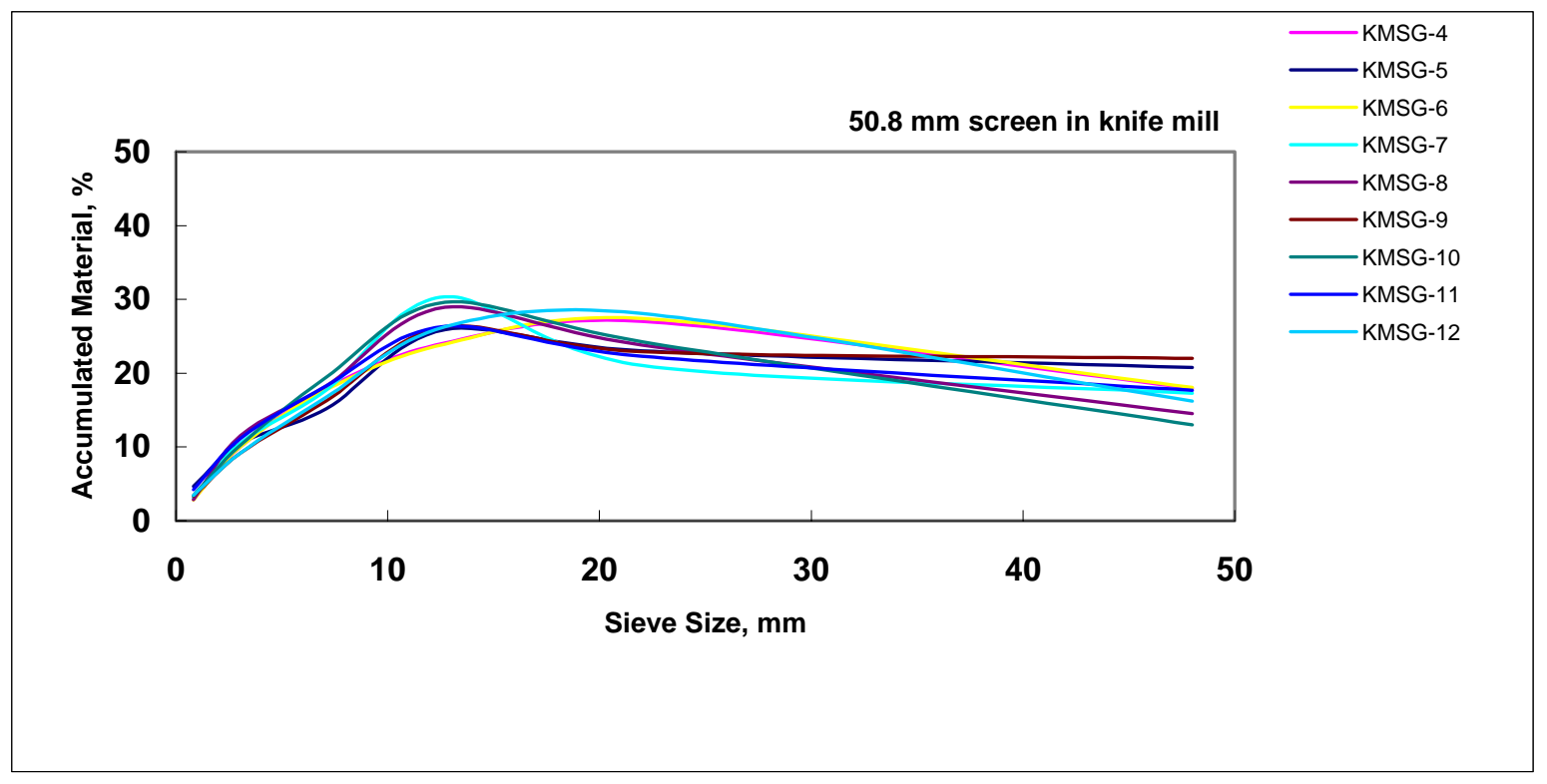

Figure 13. Sieve particle size results for switchgrass size reduction at various mass input rates and rotor speeds in a knife mill equipped with a $50.8 \mathrm{~mm}$ screen.

Table 1 Effect of biomass selection and knife mill screen size on overall geometric mean dimensions (GMD) of particle length calculated directly using sieve opening sizes and mass fraction on ASABE forage sieves, for various mass input rates and rotor speeds of knife mill.

\begin{tabular}{cccc}
\hline Biomass & $\begin{array}{c}\text { Knife mill } \\
\text { Screen size }\end{array}$ & $\begin{array}{c}\text { Geometric Mean Dimensions } \\
(\text { GMD) of Particle Length } \\
\text { Mean } \\
(\mathrm{mm})\end{array}$ & $\begin{array}{c}\text { Ratio of GMD to Knife mill } \\
\text { Screen Size }\end{array}$ \\
\hline Corn Stover & 12.7 & 3.62 & 0.28 \\
Corn Stover & 19.1 & 5.77 & 0.30 \\
Corn Stover & 25.4 & 7.68 & 0.30 \\
Corn Stover & 50.8 & 14.01 & 0.28 \\
Switchgrass & 12.7 & 3.05 & 0.24 \\
Switchgrass & 19.1 & 5.10 & 0.27 \\
Switchgrass & 25.4 & 9.27 & 0.36 \\
Switchgrass & 50.8 & 13.04 & 0.26 \\
Wheat Straw & 12.7 & 3.46 & 0.27 \\
Wheat Straw & 19.1 & 4.58 & 0.24 \\
Wheat Straw & 25.4 & 6.91 & 0.27 \\
Wheat Straw & 50.8 & 10.87 & 0.21 \\
\hline
\end{tabular}


GMD values based on image analysis of actual switchgrass particles retained by ASABE sieves and mass fractions revealed interesting trends (Figs $14-15$ ):

- GMD of switchgrass particle length was about 5 times greater than the GMD calculated using ASABE sieve opening sizes and mass fraction on sieves (Fig 14).

- GMD of switchgrass particle width was about one-third of the GMD calculated using ASABE sieve opening sizes and mass fraction on sieves (Fig 15).

These results emphasize that sieve analyses of irregular shaped particles provide relative comparisons, and that actual dimensions of particles residing on sieves differ and are not necessarily represented by sieve sizes above and below the sample.

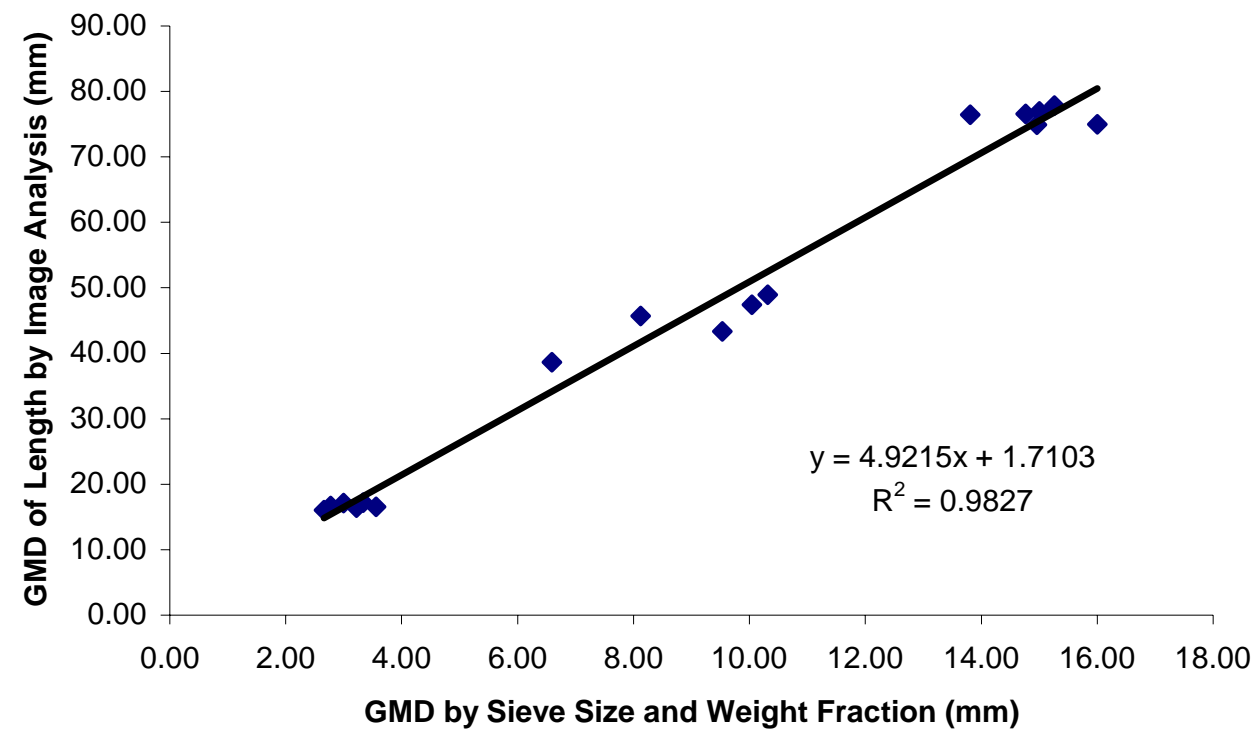

Figure 14. Comparison of switchgrass particle geometric mean dimensions (GMD) of particle length calculated using image analysis of representative samples and mass fraction from each sieve of ASABE forage standard versus GMD calculated directly using sieve opening sizes and mass fraction on ASABE forage sieves. 


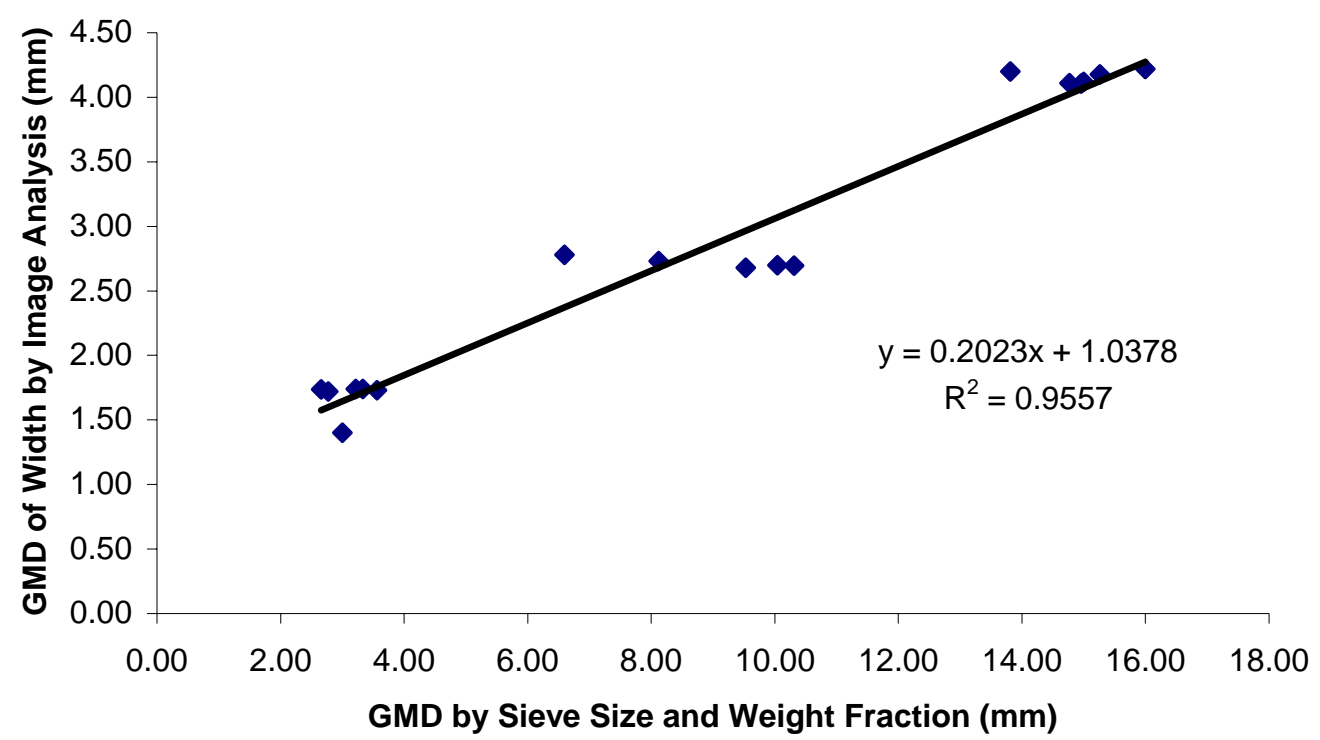

Figure 15. Comparison of switchgrass particle geometric mean dimensions (GMD) of particle width calculated using image analysis of representative samples and mass fraction from each sieve of ASABE forage standard versus GMD calculated directly using sieve opening sizes and mass fraction on ASABE forage sieves.

\section{Conclusions}

- Knowledge of mechanical biomass size reduction is limited, and is sorely needed to provide predictable delivery of uniform quality biomass for conversion.

- Effective specific size reduction energy quantifies power actually reaching biomass.

- Optimizing the energy efficiency of size reduction for a mill may be a function of operating speed, mass input rate, and screen size. For a knife mill with a classifying screen, total specific energy increased with operating speed, decreased with increasing mass input rate, and increased with reduced screen sizes.

- Particle size distribution was also attributed to operating speed, mass input rate, and screen size.

- Calculation of Geometric Mean Dimensions (GMD) from sieve sizes and mass fractions on sieves provides comparative data - but has limited utility for irregular shaped biomass particles.

- Actual switchgrass GMD (by image analysis) of particle length was about 5 times greater than the GMD calculated using ASABE sieve opening sizes and mass fraction on sieves.

- Actual switchgrass GMD (by image analysis) of particle width was about one-third of the GMD calculated using ASABE sieve opening sizes and mass fraction on sieves.

- Consensus standards for particle size distributions of biomass are needed so that critical sizes needed for conversion processes can be adequately communicated with size reduction processes. 


\section{Acknowledgements}

This research was supported in part by the USDA-NRCS Grant Agreement 68-3A75-4-136 and USDA-DOE Biomass Research and Development Initiative DE-PA36-04G094002.

\section{References}

ANSI/ASAE S424.1, DEC01. 2006. Method of determining and expressing particle size of chopped forage materials by screening. ASABE Standards, ASABE, St. Joseph, MI.

Balk WA. 1964. Energy requirements for dehydrating and pelleting coastal bermudagrass. Transactions of the ASAE 4:349-351;355

Ebling JM, Jenkins BM. 1985. Physical and chemical properties of biomass fuels. Transactions of the ASAE 28(3):898-902.

Foutch, G.L., G.C. Magruder, and J.L. Gaddy. 1981. Production of ethanol and methane from corn stover. In Agricultural Engineering, ASAE, St. Joseph, MI, p:299-304.

Hill B, Pulkinen DA. 1988. A study of the factors affecting pellet durability and pelleting efficiency in the production of dehydrated alfalfa pellets. A Special Report. Saskatchewan Dehydrators Association, Tisdale, SK, Canada.

Mani, S., L.G. Tabil, and S. Sokhansanj. 2002. Grinding performance and physical properties of wheat and barley straws, corn stover, and switchgrass. Paper No. 026175. ASAE, St. Joseph, MI.

Raman, K.P., W.P. Walawender, Y. Shimizu, and L.T. Fan. 1981. Gasification of corn stover in a fluidization bed. In Agricultural Engineering, ASAE, St. Joseph, p 335-337.

Samson P, Duxbury P, Drisdelle M, and Lapointe C. 2000. Assessment of pelletized biofuels. Available at: http://reap.ca/Reports/pelletaug2000.html. Accessed 20 June 2001.

Simonton, W. and J. Pease. 1993. Orientation independent machine vision classification of plant parts. Journal of Agricultural Engineering Research 54(3):231-243.

Walsum, G.P., S.G. Allen, M.J. Spenser, M.S. Laser, M.J. Antal, L.R. Lynd. 1996. Conversion of lignocellulosics pretreated with liquid hot water to ethanol. Applied Biochemistry and Biotechnology 57/58:157-169. 